\title{
Identidades em construção na voz de uma professora egressa de letras e suas expectativas de bases de conhecimento do professor
}

\section{Identities under construction in the voice of a graduate language teacher and her expectations of teacher knowledge bases}

\author{
Célia Carrião Jasnivski ${ }^{1}$; Alessandra Augusta Pereira da Silva ${ }^{2}$
}

Resumo

A partir de subsídios da Análise Crítica do Discurso e da Linguística Sistêmico Funcional, neste artigo temos o objetivo de analisar o modo como uma professora de língua inglesa percebe suas bases de conhecimento adquiridas no Curso de Letras, bem como o conhecimento ideal e idealizado que julga necessário ao professor da área. Ao mesmo tempo em que analisamos o modo como sua identidade de professora de língua inglesa se constitui por meio de seu discurso. Com este trabalho, pretendemos contribuir para a área de formação de professores de línguas, mais especificamente para a área das pesquisas que tratam da identidade do professor de língua estrangeira. Para isso, apoiamos nossa pesquisa nos pressupostos teóricos subjacentes à análise realizada, retomando as definições tanto de identidade, como das bases de conhecimento do professor e os procedimentos de análise de discurso, postulados primordialmente pela Análise Crítica do Discurso e pela Linguística Sistêmico Funcional. Os estudos apontam para uma representação negativa e um descontentamento quanto a sua formação inicial, sobretudo pela ineficácia no ensino da língua em que atuariam como professores.

Palavras-chave: Identidade. Bases de Conhecimento. Análise Crítica do Discurso.

\begin{abstract}
Drawing on Critical Discourse Analysis and Systemic Functional Linguistics, this article aims to analyze how an English Language teacher perceives her knowledge bases acquired in a Language course as well as the ideal and idealized knowledge deemed, in her view, necessary for a teacher of this area, while we analyze how her identity as a graduate English language teacher is represented through her discourse. With this work we intend to contribute to the area of language teacher education, more specifically to the area of research dealing with the identity of the foreign language teacher. For this, we support our research in theoretical assumptions underlying the analysis performed, incorporating both definitions of identity and the teacher's knowledge bases and procedures of discourse analysis, postulated primarily by Critical Discourse Analysis and Systemic Functional Linguistics. The studies point to a negative representation and a dissatisfaction with her initial training, especially due to the ineffectiveness of English teaching in which they would work as teachers.
\end{abstract}

Keywords: Identity, Knowledge Bases, Critical Discourse Analysis.

\footnotetext{
${ }^{1}$ Mestranda em Estudos da Linguagem na área de Ensino/Aprendizagem e Formação de Professores de Língua Estrangeira pela Universidade Estadual de Londrina e professora e coordenadora do Centro de Línguas CELIN/UNESPAR/FECILCAM. E-mail: celia_cj@hotmail.com

${ }^{2}$ Doutoranda em Estudos da Linguagem na Universidade Estadual de Londrina e professora do departamento de letras da Universidade Estadual do Paraná, UNESPAR/FECILCAM, campus de Campo MourãoE-mail: alessandrafecilcam@yahoo.com. br
} 


\section{Introdução}

[...] identities are relational: who one is is a matter of how one relates to the world and to other people.

Fairclough

A afirmação acima, feita por Fairclough (2003, p. 166), é o pressuposto inicial deste trabalho, que tem como intuito investigar os traços identitários de uma professora egressa de um curso de Letras de uma Universidade Estadual do Estado do Paraná. A partir de subsídios da Análise Critica de Discurso (ACD) e da Linguística Sistêmico Funcional (LSF), acreditamos que a constituição da identidade possa ser investigada por meio de discursos produzidos em textos, ao focarmos a análise no modo como a pessoa se relaciona com o mundo. No caso específico deste artigo, essa ideia se aplica ao modo como a participante percebe suas bases de conhecimento e se constitui como ser humano e professora de língua inglesa.

Como alunas inseridas em programa de Pós Graduação Stricto Sensu, nos propusemos, de modo mais amplo, a discutir a constituição da identidade do professor de língua inglesa, a partir de representações de uma aluna egressa de curso de Letras.

Para alcançarmos esse objetivo geral, um questionário foi elaborado e pilotado junto a quatro professores do referido curso de Letras. O questionário é constituído de três partes, contendo quadros informativos; mapeamento e cinco perguntas abertas $^{3}$. Porém, limitamos a análise a uma única questão, endereçada a uma das participantes para responder duas perguntas de pesquisa, sendo elas: a) No texto produzido pela participante da pesquisa, quais bases de conhecimento interpretamos serem imprescindíveis na constituição de identidade docente? e b) Com base em seu texto, que traços identitários inferimos?

As justificativas para o presente estudo têm origem na verificação de que as pesquisas que tratam da identidade do professor elencam frequentemente dificuldades do meio em que esse profissional atua (HYPÓLITO, 1999; NÓVOA et al., 1995), e trazem algumas observações acerca da formação inicial deficitária (CELANI, 2006; PAIVA, 1997). Também se observa que o professor não acredita em seu próprio trabalho, e há desvalorização da disciplina, itens que parecem ser unânimes em quase todos os contextos escolares (CRISTOVÃO, 2011) ${ }^{4}$. Assim, esta pesquisa justifica-se pela necessidade de se explorar o modo como a identidade do professor egresso de língua inglesa vem sendo constituída, mantida ou modificada nas relações entre o professorado, os contextos de ensino e as questões teórico-metodológicas do universo acadêmico.

Dessa forma, temos a intenção de abordar os pressupostos teóricos subjacentes à análise realizada, primeiramente retomando as definições tanto de identidade (BAULMAN, 2005; FAIRCLOUGH 2003; HALL, 2000), como das bases de conhecimento do professor (SHULMAN, 1986), para em seguida expor os procedimentos de análise que subsidiaram essa pesquisa, postulados primordialmente pela Análise Crítica do Discurso (FAIRCLOUGH, 1992，2010， 2003) e pela Linguística Sistêmico Funcional (HALLIDAY, 2004). Em um segundo momento, passamos à metodologia, contemplando a apresentação dos participantes da pesquisa, o instrumento de coleta dos dados e os procedimentos de análise, retomando as perguntas que nortearam nosso estudo. $\mathrm{Na}$ sequência, realizamos a análise dos dados coletados, bem como a discussão dos resultados obtidos, e, na última parte, a conclusão.

${ }^{3}$ Neste capítulo, uma descrição detalhada do questionário pode ser encontrada na seção de metodologia.

${ }^{4}$ Cristovão (Mesa Redonda proferida no Encontro Interdisciplinar da Educação na Universidade Estadual do Paraná, FECILCAM, 2011). 


\section{a análise crítica do discurso e a linguística sistêmico funcional}

Fairclough serve-se da Linguística Sistêmico Funcional (LSF) de Halliday para a operacionalização das análises da Análise Crítica do Discurso (ACD). Ao escolher a LSF, argumenta que a "LSF está profundamente preocupada com a relação entre língua e outros elementos e aspectos da vida social, e sua abordagem para a análise linguística de textos está sempre orientada para o caráter social dos textos" (FAIRCLOUGH, 2003, p. 5).

Quanto ao papel do uso da linguagem na vida social, Halliday (2004) enfatiza o caráter metafuncional da linguagem presente nos textos - função ideacional, a interpessoal e a textual, que ocorrem de maneira simultânea, construindo significados: a função ideacional da linguagem é a representação dos aspectos do mundo por meio da linguagem. A função interpessoal da linguagem refere-se à natureza interativa da linguagem ou da língua como ação. A função textual facilita as duas funções acima organizando as mensagens de forma coerente e coesa (HALLIDAY, 2004).
Enquanto Halliday explica as funções da linguagem, Fairclough prefere se referir aos tipos de significados (FAIRCLOUGH, 2003). O autor compartilha a visão de texto como sendo formas de representação do mundo físico, social e mental, porém de maneira distinta daquela postulada por Halliday. Ele entende que o discurso, como parte da prática social e na relação entre textos e eventos, figura de três maneiras: o modo de agir, o modo de representar e o modo de ser (FAIRCLOUGH, 2003), respectivamente, significados acional, representacional e identitário. Segundo o autor, o significado representacional se aproxima da função ideacional de Halliday, que aborda a representação da realidade nos textos, o significado acional observa o texto como meio de interação em eventos sociais em relação aos participantes desse evento e o significado identitário se refere à construção das identidades no discurso. Tanto o significado acional, quanto o identitário correspondem à função interpessoal de Halliday.

Como forma de ilustrar as terminologias praticadas pelos dois autores apresento o quadro abaixo, elaborado por Figueiredo (2009):

Quadro 1 - Cruzamento da visão social da linguagem, segundo a ACD e a LSF

\begin{tabular}{|c|c|c|}
\hline $\begin{array}{c}\text { Aspectos do social constituídos (em } \\
\text { parte) pelo discurso }\end{array}$ & $\begin{array}{c}\text { Significados textuais } \\
\text { (Fairclough, 2003a) }\end{array}$ & $\begin{array}{c}\text { Metafunções hallidayanas } \\
\text { (Halliday, 2004) }\end{array}$ \\
\hline Sistemas de conhecimento e crença & Representacionais & Metafunçãão interpessoal ideacional \\
\hline Relações sociais & Acionais & Metafunção interpessoal \\
\hline Identidades soiais & Identitários & \\
\hline
\end{tabular}

Fonte: Figueiredo (2009)

Tanto as metafunções de Halliday quanto os tipos de significados de Fairclough apresentam-se como formas de entendimento de discurso em relação aos aspectos da prática social (acional, representacional 
e identitário). Esta relação é para Fairclough dialética, o discurso "incorpora e é incorporado por outros elementos" (FAIRCLOUGH, 2010, p. 227) tem efeitos causais e, assim, o uso da linguagem constitui simultaneamente "identidades sociais, relações sociais e sistemas de conhecimento e crença". (FIGUEIREDO, 2009, p. 743).

Fairclough (2003) argumenta ainda que o discurso como prática social figura de três maneiras e as associa aos três tipos de significados descritos acima. Assim, para o autor, a ação está associada aos gêneros, a representação ao discurso, e a identificação, ao estilo. O Quadro 2 sintetiza essas associações:

Quadro 2 - Elementos da Prática Social (FAIRCLOUGH) associados à LSF.

\begin{tabular}{|c|c|}
\hline LSF (HALLIDAY) & ACD (FAIRCLOUGH) \\
\hline Ação & Gêneros \\
\hline Representação & Discurso \\
\hline Identificação & Estilo \\
\hline
\end{tabular}

Fonte: Halliday (2004)

Os diferentes gêneros que usamos na prática social são diferentes maneiras de agirmos e interagirmos. Por meio dos discursos, codificamos experiências e vivências do mundo e cada indivíduo tem seu estilo próprio de usar a linguagem, constituindo, assim, modos de ser, ou de se auto identificar. Assim, a análise do discurso deve estabelecer relação entre estes três tipos de significados, o contexto social no qual está inserido - o evento social, a prática social e a estrutura social, verificando, por meio, de traços linguísticos, como todos esses aspectos estão sendo articulados no texto (RESENDE, 2006).
Relacionando essa posição da teoria de Fairclough a da LSF de Halliday, Resende (2006, p. 61) postula que "[...] gêneros, discurso e estilos ligam o texto a outros elementos do social - as relações internas do texto e suas relações externas -, por isso a operacionalização desses conceitos mantem o cerne do pensamento de Halliday".

Finalizando essa caracterização da relação transdisciplinar entre as duas teorias - a ACD e a LSF -, passamos à Modalidade.

\section{Modalidade}

Uma das categorias para a operacionalização dos conceitos acima na análise de discurso é a categoria MODALIDADE. O conceito modalidade é definido por Halliday como "o julgamento do falante sobre as probabilidades ou obrigatoriedades envolvidas no que diz" (HALLIDAY, 2004, p. 75). Para Halliday, a modalidade está relacionada a um traço semântico essencial, a polaridade (RESENDE, 2006). A polaridade pode ser definida como a escolha entre o positivo e o negativo, ou entre o sim e o não; localiza-se numa "região de incerteza" entre estes dois polos, e, para o autor, a modalidade divide-se em duas subcategorias: modalização e modulação. A modalização e a modulação têm significados diferentes para proposições e propostas (HALLIDAY, 2004). Em proposições (trocas de informações), há dois tipos de possibilidades: os graus de probabilidade e os graus de frequência. Os graus de probabilidade são indicados pelo uso de advérbios do tipo 'possivelmente', 'provavelmente', 'certamente'. Já os graus de frequência variam entre 'às vezes', 'geralmente' e 'sempre' (HALLIDAY, 2004, p. 147). Em propostas (trocas de bens e serviços), o significado dos polos positivo e negativo envolve prescrever e proscrever, por exemplo, 'faça isso', 'não faça isso', respectivamente. Dentro das propostas, o autor ainda afirma que há duas possibilidades, o 
grau da obrigatoriedade 'permitido', 'esperado', 'obrigado' e o grau de inclinação: 'desejoso de', 'ansioso por', 'determinado a'. Nesta última, as escalas de obrigação ou inclinação são referidas como modulação enquanto que nas proposições, os graus de probabilidade e frequência são chamados de modalização (HALLIDAY, 2004, p. 147).

Trazendo a perspectiva teórica de Fairclough para tópico de discussão, Resende (2006) aponta duas distinções entre as perspectivas teóricas de Halliday e Fairclough, com vistas à modalidade. Primeiramente, Fairclough não faz a bipartição da modalidade em modalidade e modulação, mas unifica-as sob a denominação de modalidade. Para Fairclough (2003, p. 166, tradução nossa)

Modalidade é importante na texturização de identidades, tanto pessoal ('personalidades') como social, no sentido de que o que você se compromete é uma parte significativa do que você é - assim escolhas de modalidade em textos podem ser vistas como parte do processo de texturização de auto identidade.

Por sua propriedade dialética, a categoria modalidade está estreitamente relacionada aos três aspectos de significado nos textos - ação, representação e identificação (FAIRCLOUGH, 2003). Para o autor, a maneira com que uma pessoa representa o mundo ou como se compromete nos textos nas interações sociais, é o modo que ele forma sua identidade. Assim, "identidades são relacionais: quem a pessoa é, é uma questão de como a pessoa se relaciona com o mundo e com outras pessoas" (FAIRCLOUGH, 2003, p. 166, tradução nossa).

As escolhas de modalidades na interação com o outro não são significativas somente no âmbito da identificação, mas também na ação e representação: para o autor, modalidade pode ser vista como 'comprometimento', 'atitudes', ‘julgamentos' e 'pontos de vista' (FAIRCLOUGH, 2003, p. 166), ou seja, a modalidade tem a ver com o quanto as pessoas se comprometem ao fazerem "afirmações, perguntas, demandas ou ofertas" (RESENDE, 2006). Afirmações e perguntas estão relacionadas à troca de conhecimento, demandas e ofertas relacionam-se à troca de atividades, sendo que estas correspondem à troca de informação e à troca de bens e serviços de Halliday, respectivamente (RESENDE, 2006). Nas afirmações e perguntas (trocas de conhecimento), a modalidade é, para Fairclough, epistêmica, ou seja, "refere-se ao comprometimento com a "verdade" e nas demandas e ofertas (trocas de atividades) a modalidade é deôntica, quando se "refere ao comprometimento com a obrigatoriedade e ou/ necessidade" (RESENDE, 2006, p. 82).

Outra distinção apontada por Resende referese aos polos positivo e negativo de Halliday. Para este último autor, a modalidade se encontra numa "região de incerteza" entre os dois polos, ou entre o sim e o não, portanto os polos positivo e negativo estão fora da categoria modalidade. No entanto, para Fairclough a modalidade é mais ampla e inclui os dois polos.

A análise de modalidades nos textos pode nos ajudar, portanto, a identificar algumas representações do falante em relação às suas bases de conhecimento, bem como na identificação de alguns de seus traços identitários.

\section{Identidade}

De acordo com o pesquisador Stuart Hall (2000), pertencente à perspectiva dos Estudos Culturais, o conceito de identidade está comumente relacionado à ideia de alguma origem em comum ou como uma característica que pode identificar um grupo de pessoas, uma nação, ou até mesmo um único ideal. Segundo o autor, essa visão do conceito de identidade é vista como uma característica fixa e estável ou como uma propriedade do indivíduo, condição preexistente a ele, que desde seu nascimento já possui marcas identitárias, tais como nome, família, raça, condição social, etc. (BUCHOLTZ; HALL, 2005 apud MAYES, 2010), não sendo considerada, por esta razão, objeto de reflexão ou questionamentos. Na contramão dessa definição, Hall (2000, p. 106) aponta que "a 
abordagem discursiva vê a identificação como uma construção, como um processo nunca completado, como algo sempre "em processo"".

$\mathrm{Na}$ procura por traços identitários no discurso da nossa participante, analisamos suas respostas em convergência com a definição resenhada por Hall, contextualizando o texto pelas condições sócio subjetivas e histórico-culturais em que a produção foi efetuada, elencando informações, tais como quem é a participante da pesquisa no momento da produção escrita, na interação com o outro. A interação com o outro, o modo como o outro nos vê influenciam sobremaneira a forma como nós também nos constituímos e a forma como desejamos ser. Em outras palavras, Hall (2000, p. 109) postula que a identidade:

[...] tem a ver não tanto com as questões "quem nós somos" ou "de onde nós viemos, mas muito mais com as questões "quem nós podemos nos tornar", "como nós temos sido representados" e como essa representação afeta a forma como nós podemos representar a nós próprios.

Ainda segundo o mesmo autor, as identidades estão cada vez mais fragmentadas na modernidade tardia e são construídas dentro dos discursos, "no interior de formações discursivas específicas, por estratégias e iniciativas específicas" (HALL, 2000, p. 109).

\section{Identidade Profissional}

A fim de situarmos o nosso trabalho dentro da perspectiva da formação de professores de línguas estrangeiras, voltamos à questão da identidade para tratarmos agora da identidade profissional, com o objetivo de fornecer ao leitor uma justificativa para que a questão da identidade seja levantada nesse contexto educacional.

Segundo Bauman (2005), o ser humano tem a tendência de só perceber as coisas quando essas passam a apresentar algum sinal de problema, nas palavras do autor, "quando elas se desvanecem, fracassam, começam a se comportar estranhamente ou o decepcionam de alguma forma" (BAUMAN, 2005 , p. 23). No presente estudo, partimos do pressuposto de que as pesquisas sobre a identidade profissional do professor de língua inglesa têm origem nas constantes mudanças em que o ensino de língua inglesa no Brasil tem passado nas últimas décadas (QUEVEDO-CAMARGO; RAMOS, 2008), sendo o professor aquele que tem o papel central com a função de implementar essas mudanças no seu contexto de trabalho. Visto que toda mudança gera desconfortos, surgem nesse contexto angústias, dúvidas, e incertezas, e as noções de certo ou errado parecem estar muito próximas, bem como surgem dúvidas acerca do que ensinar, como ensinar e para que ensinar. Tendo em vista essa afirmação, adotamos os pressupostos teóricos da Análise Crítica do Discurso (ACD), como princípio norteador para a análise dos dados coletados junto a nossa participante, uma vez que eles serão tomados como discursos registrados dentro da história.

Tendo dito isso, passamos agora para uma breve discussão sobre as bases do conhecimento necessárias ao professor de língua inglesa, visto que em uma de nossas perguntas de pesquisa, este assunto é levantado.

\section{as bases de conhecimento do professor}

Quando esta questão está vinculada à literatura acadêmica, Lee S. Shulman apresenta-se como um grande nome, haja vista sua contribuição para a área educacional em pesquisas que tratam das bases de conhecimento profissional para o ensino e docência.

Shulman (1986) argumenta que existia uma lacuna nas pesquisas na área de formação e desenvolvimento profissional de professores, pois, segundo ele, as pesquisas até então existentes referiam-se às ações do professor ou questões mais pragmáticas, do tipo, como o professor gerenciava suas aulas, como ele se organizava, formulava 
questões, planejava suas aulas, dentre outras. Para Shulman, existiam nas pesquisas o que ele denomina "paradigma perdido" onde tais estudos ignoravam o que ele caracteriza como um aspecto fundamental no ensino: o conteúdo específico da disciplina. Segundo o autor:

\begin{abstract}
Ninguém perguntou como o conteúdo específico era transformado a partir do conhecimento do professor para o conteúdo da instrução. Nem perguntaram como formulações particulares daquele conteúdo se relacionavam com que os alunos vieram a saber ou aprender de forma errada . (SHULMAN, 1986, p. 6)
\end{abstract}

Dessa forma, Shulman considera "o paradigma perdido" uma problemática muito séria, pois envolve questões políticas e de pesquisa, e, com o intuito de preencher essa lacuna, Shulman e outros pesquisadores tomam como base as seguintes perguntas direcionadoras:

Quais são as fontes de conhecimento do professor? $\mathrm{O}$ que um professor sabe e quando ele ou ela veio a saber? Como o novo conhecimento é adquirido, como o velho conhecimento é recuperado, e ambos combinados para formar uma nova base de conhecimentos? (SHULMAN, 1986, p. 8).

Baseado nestas perguntas, o autor afirma que os professores precisam ter diferentes tipos de conhecimento sendo as principais: conhecimento da disciplina, conhecimento de conteúdo pedagógico e conhecimento curricular. Esses conhecimentos são apresentados de várias formas, tais como proposições (conhecimento proposicional), casos (conhecimento de casos) e estratégias (conhecimento estratégico).

O conhecimento da disciplina é o conhecimento pelo professor da matéria que ele leciona, tais como conceitos, estruturas, regras e as especificidades de cada área. Porém, para o autor, o professor precisa entender mais do que somente a matéria que ensina, ele precisa entender o por quê as coisas são da maneira em que estão postas. (SHULMAN, 1986).

Quanto ao conhecimento de conteúdo pedagógico, este se refere às formas de representação, por meio de exemplos, ilustrações, analogias, explicações e demonstrações utilizadas pelo professor de forma a tornar o conteúdo compreensível para seus alunos. Para o autor, o conhecimento de conteúdo pedagógico faz com que determinados assuntos sejam fáceis ou difíceis para os aprendizes e com que o professor saiba lidar com as concepções e as preconcepções que os alunos trazem para o contexto de ensino/aprendizagem.

$\mathrm{O}$ conhecimento curricular refere-se ao conhecimento pelo professor, da variedade dos programas preparados para o ensino de determinados assuntos em níveis específicos, bem como o conhecimento da gama de materiais didáticos disponíveis em relação a esses programas curriculares em sua determinada área.

Mateus (2005) apresenta outras quatro variedades de conhecimento acrescentadas por Shulman em 1987. São elas: o conhecimento pedagógico geral, que se refere ao conhecimento dos aspectos gerais que abrangem o processo de ensinar e aprender envolvendo o manejo de sala de aula, grupos de trabalho e questões de gestão de escola, por exemplo; o conhecimento dos alunos e de suas características; o conhecimento do contexto educacional, incluindo desde questões micro como a sala de aula até questões que envolvem as comunidades e culturas de onde atua e finalmente, conhecimento dos fins, propósitos e valores educacionais e de seus fundamentos históricos e filosóficos.

Quevedo-Camargo, El Kadri e Ramos (2011) faz um apanhado geral dos pesquisadores posteriores a Shulman que publicaram trabalhos nesta área de conhecimento, inclusive pesquisadores como Johnson e Freeman (2001), que tratam especificamente da questão do ensino de línguas. No contexto brasileiro, a autora cita Almeida Filho (1999, 2000, 2004) e Basso (2001), que tratam da competência necessária ao professor de língua estrangeira.

As pesquisas de Johnson (2009) configuram-se no trabalho mais recente nesta área de conhecimento citado por Quevedo-Camargo. Com base em Johnson, QuevedoCamargo, El Kadri e Ramos (2011, p. 92), postula que 
[...] a base de conhecimento dos professores de línguas compõe-se de três grandes áreas: (1) o conteúdo dos programas de formação de professores de línguas (o que os professores precisam saber); (2) as pedagogias que são ensinadas nesses programas (como os professores devem ensinar); e (3) as formas institucionais de ensino por meio das quais o conteúdo e as pedagogias são aprendidas (como os professores aprendem a ensinar).

Retomando a pesquisa de Shulman (1986) e comparando-a com o trabalho de Johnson (2009), percebemos que as pesquisas desta última autora podem ser equiparadas com as três grandes áreas das bases de conhecimento do professor postuladas por Shulman - conhecimento do conteúdo específico, conhecimento pedagógico geral e conhecimento pedagógico do conteúdo. Podemos afirmar, assim, queasbasesdeconhecimentonecessáriasao professor continuaram a ser consideradas e expandidas por outros autores. Dessa forma, embora as propostas de Shulman possam parecer prescritivas, e reflitam o seu tempo histórico e lugar social, salientamos a contribuição deste teórico para os programas de formação de professores nos dias atuais. A importância da noção de base de conhecimento do professor se faz ainda viva, presente e muitíssimo importante diante de programas de formação de professores que talvez falhem pelo desejo de adesão à atualidade, em detrimento de equilíbrio e tipos de conteúdos, habilidades para os profissionais da linguagem.

Trazendo a discussão acerca das bases de conhecimento para o contexto de pesquisa, entendemos que elas, interpretadas por meio de análise, possibilitam discutir traços identitários do professor.

\section{Metodologia de pesquisa}

Um de nossos grandes desafios como pesquisadores é a produção de conhecimento sistematizado, sem, contudo, negar as características sócio subjetivas que constituem nossa identidade como ser humano. Nesse viés, partimos do pressuposto de que o sujeito, no mundo físico, produz um enunciador que, por sua vez, enuncia na ordem do expor ou narrar, criando, para isso, personagens ${ }^{5}$ (HABERMAS, 1987, 2004) no texto. Considerando o fato de a presente pesquisa ter se originado de uma inquietação acerca de uma realidade na qual estamos envolvidas, descartamos a existência de certa neutralidade nas escolhas e eventualmente na pesquisa. Ao escrevermos este artigo, estamos cientes dessa condição em que nos inserimos e intuímos destacar para o leitor. Sendo assim, também consideramos importante nos inserirmos como participantes desta pesquisa, na condição de pesquisadoras e sujeitos imbuídos de representações sobre o mundo que nos cerca, representações essas que compõem nossas identidades.

Ambas somos professoras de língua inglesa atualmente, em contextos educacionais diferentes. Uma atua como professora na rede estadual de ensino superior, em um curso de Letras de uma universidade do Paraná, desde 2005; coordena um curso de pós graduação lato sensu e possui atividade administrativa na instituição. A outra atua como professora em escola de idiomas vinculada a uma instituição de ensino superior, e ocupa atualmente função administrativa como coordenadora pedagógica. Atualmente, ambas são alunas do programa de pós-graduação Stricto Sensu em ensino aprendizagem e formação de professores de língua estrangeira. $\mathrm{O}$ fato de ambas terem vivido no contexto em que a coleta de dados foi realizada fornece sobre este informações privilegiadas.

A participante da pesquisa, cujos dados foram analisados, é egressa do curso de Letras de uma instituição pública do interior do Paraná, tendo -se graduado em 2009. Atualmente é aluna de um programa de pós graduação Stricto Sensu de uma

${ }^{5}$ Nos baseamos na teoria dos mundos representados propostos pelo autor supracitado, dentro do quadro das coordenadas dos mundos objetivo, social e subjetivo. O texto encontra-se no nível social e subjetivo, estando, portanto, no nível das interpretações sobre o mundo objetivo). 
universidade estadual da região noroeste do Paraná, em estudos literários. Ela possui experiência em escolas de idiomas e alguns meses de experiência no ensino fundamental e médio e ensino superior. Quando ingressou no curso de Letras havia estudado inglês por seis anos e lecionava em escolas de idiomas.

$\mathrm{O}$ interesse nessa participante deu-se pelo fato de nos questionarmos como o professor recém-formado se vê enquanto professor em serviço. Além disso, ela é uma participante que no momento apresentase para nós como uma pessoa de fácil acesso para compartilharmos a análise para que ela possa reagir frente ao texto, pois acreditamos, corroborando com a visão da pesquisa qualitativa crítica, que não existe interpretação pura dos fatos (KINCHELOE; McLAREN, 2006), já que não somos neutros.

Um questionário foi o instrumento de nossa coleta de dados e ele é constituído por três partes que chamaremos, sucessivamente, de 1) Quadros informativos; 2) Mapeamento e; 3) Perguntas abertas. A primeira parte do questionário é formada por dois quadros informativos sobre as participantes. O primeiro quadro trata da formação acadêmica e profissional e o segundo, da atuação profissional. A segunda divisão do instrumento teve como foco a busca de se elaborar um mapeamento sobre as competências linguísticas das participantes a partir de suas próprias representações, por meio de perguntas fechadas, segundo o Quadro Europeu Comum para as Línguas (QECR) ${ }^{6}$. Já a última parte do questionário consta de cinco perguntas abertas, referentes à reestruturação do curso de Letras.

O contato com a participante foi feito via e-mail em maio de 2011 e procuramos assegurar-lhe a confiabilidade e a seriedade da pesquisa já no corpo da mensagem, fornecendo uma breve explicação a respeito do motivo do nosso contato, o objetivo da pesquisa e a solicitação de manifestar ou não desejo em participar da pesquisa. Tendo obtido seu aceite, enviamos-lhe o questionário logo em seguida, procurando certificá-la de que seu anonimato e sua privacidade seriam preservados, com a garantia de que seu nome não seria revelado. Recebemos o retorno no dia seguinte ao envio, observando que a participante levou 35 minutos para responder todas as questões, já que o instrumento requer o registro do horário do início e término para o preenchimento.

Em síntese, utilizamos como instrumento de pesquisa um questionário piloto e adotamos como procedimentos de análise a categoria MODALIDADE para responder a duas perguntas de pesquisa: a) Nos textos produzidos pelas participantes da pesquisa, que componentes da base de conhecimento são imprescindíveis na constituição da identidade docente? e b) Com base em seu texto, que traços identitários inferimos? Estas são as perguntas que nos propomos a responder na sequência. A categoria ora apresentada se torna, portanto, uma ferramenta imprescindível para a compreensão de representações já que, a partir de autores supracitados, tais como Fairclough e Resende, podemos concluir que tais marcas linguísticas permitem evidenciar processos de textualização de auto identidades.

\section{Análise de dados e discussão dos resultados}

A análise dos dados coletados e a discussão dos resultados estão organizadas a partir das perguntas da pesquisa realizadas neste artigo. Comecemos

${ }^{6} \mathrm{O}$ Quadro Europeu Comum de Referência para Línguas (QECR) é um documento de 260 páginas elaborado por peritos que compõem o chamado Conselho da Europa. Para este estudo, utilizamo-nos do quadro 2 onde constam os níveis comuns de referência para autoavaliação. Neste quadro, constante nas páginas 53 a 55 do documento, as competências no uso da língua são descritas numa escala global de seis níveis de proficiência, que apresentam definições gerais de desempenho linguístico: A1 e A2 (usuário básico), B1 e B2 (usuário independente), C1 e C2 (usuário proficiente). Cada um desses níveis é dividido em descritores (can-do statements), que abrangem muitas outras competências que constituem as capacidades que um usuário da língua tem em um determinado nível em relação a cinco habilidades agrupadas em três áreas: compreensão (leitura e audição), fala (interação e produção orais) e escrita. 
pela primeira pergunta de pesquisa, a seguir.

\section{PERGUNTA 1: Nos textos produzidos pelas} participantes da pesquisa, que componentes da base de conhecimento são imprescindíveis na constituição da identidade docente?

Ao responder a pergunta acima, sem falar explicitamente das bases de conhecimento necessárias para o professor, a participante da pesquisa, avalia o curso de Letras e o que o professor precisa ou o que falta a ele. Ela faz referência a alguns aspectos que seriam imprescindíveis no curso para que um professor de língua inglesa pudesse ser formado. É por meio da análise dessa avaliação que conseguimos responder a essa questão, destacando os principais componentes da base de conhecimento necessária ao professor, segundo a participante. São elas: a) conhecimento teórico e b) conhecimento linguístico.

Em vários momentos do texto, a participante postula sobre a importância do conhecimento teórico como base de conhecimento para o professor, dentre os quais destacamos os seguintes, a título de ilustração:

[...] e as poucas pesquisas que realizei contribuíram muito para minha formação, para conhecer as teorias atuais e as novas propostas das DCEs. Também contribuíram para a minha atuação profissional, pois tenho a intenção (e já lecionei) de lecionar no ensino superior, onde as pesquisas são super importantes.

A respondente relata a sua experiência com pesquisas na sua formação inicial e destaca a importância delas no curso de formação de professores. Essa interpretação dos dados foi feita a partir das marcas linguísticas que se apresentam no texto, com recurso à modalidade, majoritariamente deôntica. As marcas linguísticas em destaque revelam seu comprometimento com a necessidade das pesquisas na formação inicial e na prática por meio da afirmação categórica (ausência de incerteza: contribuíram; são) e modulada por intensificação (uso dos advérbios de alta intensidade: muito, que incide sobre o processo contribuiram; e super que intensifica a qualidade importante).

Tanto no excerto acima como nos seguintes, destacamos exemplos das funções da linguagem e seus componentes funcionais dos significados presentes na sua forma de enunciar:

[...] o professor também tem que ter uma boa bagagem teórica, não ficar sempre ensinando da mesma forma e as mesmas coisas, precisa se atualizar, saber sobre as novas propostas [...] isto (a metodologia) contribuiu muito para minha formação, já para minha atuação profissional nem tanto, pois a realidade é bem diferente do que é dito na teoria.

[...] as contribuições teóricas foram muito boas e me ajudaram a me preparar para dar aula no ensino regular, realidade que eu não conhecia.

Destacamos novamente o uso de advérbios intensificadores de qualidade em muito boas relativos à bagagem teórica e o uso do advérbio modal em contribuiu muito a respeito das contribuições teóricas, argumentando sobre sua opinião quanto aos conjuntos de conhecimentos necessários/obrigatórios ao professor. Lemos nos dados instâncias concretas do uso de modalidade deôntica, fazendo prescrições (em tem que ter, precisa, saber) e proscrições ao professor (não ficar). Os processos relacionais atributivos (é bem diferente; foram muito boas) e mental (ajudaram) pertencem à modalidade epistêmica (HALLIDAY, 2004), por meio de afirmações polarizadas positivamente, isto é, categóricas afirmativas. Além do alto envolvimento e comprometimento com o seu enunciado, o que chama a atenção é a posição que a participante assume, quando ela usa o agente $o$ professor. $\mathrm{O}$ uso de dêiticos pronominais de terceira pessoa do singular se referem ao profissional da área, por meio do qual representa o ator social por sua classe, porém não se inclui, haja vista a ausência do dêitico de primeira pessoa e do uso de verbos com sujeito implícito. Nossa interpretação é a de que a obrigatoriedade ou necessidade do professor saber a teoria é expressa de forma universal (FAIRCLOUGH, 2010), assim revelando a modalidade objetiva (RESENDE, 2006). Em outras palavras, a base subjetiva do julgamento que ela faz do que seja necessário ou obrigatório ao professor 
de uma forma geral está implícita, e este traço revela o caminho persuasivo que pretende com seus argumentos envoltos pelas formas de modalidade ilustradas.

A relação entre a autora do texto e a representação é fundamental no estudo das modalidades não somente para o significado identificacional (RESENDE, 2006), mas também para os significados acionais e representacionais, sendo que, por meio dos excertos acima, vemos a dialética entre os três aspectos do significado. No seu estilo próprio de representar suas experiências e a realidade (significado representacional), ela constitui o seu modo de ser ou de se autoidentificar (significado identificacional), significados esses que são concretizados por meio do texto (significado acional). Todos esses significados são afetados pelo processo da relação social em que os elementos do discurso estão envolvidos, o evento social, a prática social e a estrutura social.

Aausência da modalidade subjetiva e a predileção do uso do dêitico de $3^{\mathrm{a}}$ pessoa do singular leva a caracterização do seu discurso como hegemônico (FAIRCLOUGH, 2003). O fato de o professor saber teoria figura-se como discurso politicamente correto no meio acadêmico, de forma que, atenuando seu discurso, a participante assume uma posição confortável, pois não poderá ser contestada pelo seu interlocutor.

Não encontramos nos dados subsídios que argumentem em que sentido o conhecimento teórico auxilia a prática da professora. Por outro lado, lemos contradição em um dos seus excertos, discurso bastante recorrente entre o professorado e até mesmo nos cursos de formação: a realidade $\boldsymbol{e}^{-}$ bem diferente do que é dito na teoria. Com o uso do processo relacional atributivo (verbo ser no presente do indicativo), ao mesmo tempo em que ela afirma ter sido a pesquisa fator importante para sua formação, ela se contradiz, apontando a dissonância entre algo real (ou seja, a prática) de algo abstrato (realidade $\mathrm{x}$ teoria).
Concluímos, assim, que a participante reconhece a importância da teoria como base de conhecimento para o professor e, ao mesmo tempo em que argumenta de forma assertiva, com o uso de modalidades majoritariamente deônticas, ela se submete e reproduz discursos que historicamente sub posicionam o professor e reduzem o valor de sua educação formal.

Podemos afirmar também, por meio da análise, que todo o discurso da participante é perpassado pela ênfase que ela dá à importância do conhecimento linguístico necessário ao professor. Portanto, são muitos os excertos que podemos destacar para discussão. Vejamos o primeiro:

[...] Algumas ementas preveem que os alunos saibam apenas preparar aulas com gêneros, conduzir discussões sobre a sociedade, mas e a língua? Quando os alunos aprenderão a Língua Inglesa, que deve permear todo seu trabalho em sala de aula?

No trecho acima, marcado pela conjunção adversativa mas, bem como pela pergunta aberta que se inicia com quando, a respondente marca seu posicionamento quanto ao ensino de língua inglesa em sua formação inicial. Primeiramente percebemos que sua noção de língua parece diferir da noção de língua como discurso, quando, ao afirmar que preparar aulas com gêneros e conduzir discussões sobre a sociedade não fazem parte do aprendizado da língua, sendo que tal afirmação é ainda mais reforçada pela palavra denotativa de restrição apenas. Quando usa a conjunção adversativa mas em forma de questionamento, ela estabelece relação de oposição quanto ao que foi afirmado anteriormente - a 'verdade' é postulada somente após essa marca linguística e, por conseguinte, subentende-se que o curso não oferece o aprendizado da língua inglesa, da maneira como ela a concebe.

Outro fator a ser observado são os dois questionamentos presentes em seu enunciado. Tanto a pergunta que se inicia com a conjunção adversativa mas, quanto a que se inicia com o advérbio temporal quando leva-nos à interpretação do não dito, ou seja, os alunos não aprendem 
língua inglesa no curso de Letras pois, por meio dessas marcas linguísticas, ela projeta esta prática para o futuro. Ambas as perguntas são retóricas e servem como tom intimista buscando envolvimento e aproximação entre enunciador e interlocutor de forma a obter deste último aprovação sobre o que está sendo dito. Interpretamos também que, segundo a participante, para aprender a língua, os professores em pré-serviço precisam ser expostos à forma da língua, como podemos comprovar no excerto a seguir:

[...] É imprescindível o conhecimento da língua, o máximo possível. Conhecer vocabulário, pronúncia, pontos gramaticais, expressões.

O uso do verbo atributivo é, asseverado junto ao qualificador imprescindivel ilustra outro exemplo de modalidade epistêmica. Por meio da afirmação categórica afirmativa, ela demonstra ao mesmo tempo certeza, bem como obrigatoriedade em agir, atribuindo um traço de inevitabilidade oferecendo uma solução para o problema. Chama-nos atenção o fato do agente estar oculto no enunciado. Uma possível reconstrução seria: é imprescindivel que o professor conheça a língua o máximo possivel, onde o agente fica explícito. O recurso utilizado é chamado por Fairclough (2003) de nominalização, que serve como modo de generalizar ou esconder o agente e/ou paciente. A forma escolhida pela participante, além de esconder o agente, funciona como uma maneira de atenuar o caráter deôntico da expressão destacada, assim, neste momento da fala, ela se exime da responsabilidade de prescrever ações ao professor.

Em conformidade com as questões expostas acima, interpretamos que na opinião da participante, a base do conhecimento do professor de língua inglesa é a própria língua, portanto, o conhecimento de conteúdo, formulado no discurso por meio de complementos nominais relativos às habilidades linguísticas expressas em inglês (no excerto a seguir). Para que os alunos adquiram essa base, o profissional de hoje e os de amanhã, representados explicitamente por suas classes, e a instituição, aludida implicitamente por referência a espaços materiais de uso coletivo, especialmente preparados para o desenvolvimento de habilidades linguísticas:

[...] também é preciso estrutura física adequada para realizar atividades de listening (como laboratório de línguas), de speaking, de writing e reading. $\mathrm{O}$ professor precisa ter acesso a TV, som, vídeo, todos os equipamentos que são utilizados em cursos de línguas para que os alunos adquiram fluência.

O uso da expressão é preciso trata de outro exemplo de modalidade utilizada de forma atenuada, ofuscando o agente, neste contexto, a instituição de ensino superior. No entanto, no turno de fala acima, tanto as formas modais é preciso, quanto precisa ter denotam necessidade e não mais obrigatoriedade, como no exemplo anteriormente comentado.

Os documentos normativos do curso de Letras requerem atenção:

[...] Além disso, os alunos de Letras devem fazer mais atividades de speaking. As ementas devem ser revistas, para que estejam de acordo com o objetivo: que os alunos saiam com fluência na língua.

No excerto imediatamente acima, observamos o uso de duas afirmações deônticas servindo-nos como prescrição ideal para o curso de formação (devem). Notamos o uso da voz passiva no trecho as ementas devem ser revistas. Para Fairclough (2010; 1992), a escolha pela passiva pode ter razões diversas. Nesse caso, acreditamos que esta serve como forma de enfraquecer novamente o caráter deôntico, evitando a responsabilidade de atribuir explicitamente funções aos professores formadores, o que poderia soar de forma negativa, por exemplo, em uma formulação como esta: os professores devem rever as ementas. Na formulação acima, o objeto da revisão (ementas) ocupa a posição temática na frase, ficando implícito quem deve exercer a ação.

Ainda explorando o último excerto, a participante vale-se do presente do modo subjuntivo que os alunos saiam para mais uma vez argumentar sobre algo esperado, referindo-se ao aprendizado de língua inglesa de forma hipotética, isto é, virtual, e projetando a prática para a mesma dimensão, o que seria o objetivo do curso de Letras. Assim, a 
participante, produz seu discurso com o uso de afirmações majoritariamente deônticas, quando se refere a estrutura física do curso, necessários e/ ou obrigatórios para o ensino e aprendizagem da língua. Utiliza a voz passiva para ofuscar o agente, como forma de atenuar o caráter deôntico quando se refere aos documentos normativos do curso.

\section{PERGUNTA 2: Com base em seu texto, que traços identitários inferimos?}

Nas críticas que ela faz ao curso de Letras, é possível verificar a forma como ela encaminha seus pontos de vista com relação ao material pedagógico de apoio para o professor formador, à metodologia utilizada, ao modo como o planejamento da disciplina está estruturado, ao número de aulas oferecidas para a disciplina de língua inglesa. A respondente usa tanto afirmações epistêmicas quanto afirmações deônticas na maioria de seus argumentos, o que faz com que ela tenha alto grau de comprometimento em relação 'a verdade' que enuncia, ao mesmo tempo em que demonstra comprometimento com a obrigatoriedade e/ou necessidade de mudança. O seu estilo de escrita, a maneira com que ela se compromete nos textos é uma parte importante de como ela própria se identifica e como molda sua identidade (FAIRCLOUGH, 2003). Ela informa e argumenta com autonomia de quem conhece e deixa transparecer que, no período em que era aluna do curso, sua identidade profissional já se fazia presente, pois observava as condições de trabalho do professor, o modo como o professor direcionava suas aulas, sua metodologia e o que lhe faltava para que o aprendizado realmente acontecesse: (as ementas devem ser revistas, é preciso estrutura física adequada, o professor precisar ter acesso a TV [..].

Em nossa interpretação, a participante apresenta traços de um personagem dialógico(FAIRCLOUGH, 2003), que opta por interagir com seu interlocutor ao fazer perguntas, propositadamente retóricas: (mas, e a língua; Quando os alunos aprenderão a língua inglesa [...]?), requisitando ao leitor créditos de veracidade dos fatos descritos, calcados no conteúdo de sua experiência. Além disso, ela assertivamente prescreve ações ao professor (o professor [...] precisa se atualizar, saber sobre as novas propostas [...]) ao mesmo tempo que suaviza o caráter deôntico de suas afirmações quando usa a voz passiva (as ementas devem ser revistas), nominalizações (é imprescindível o conhecimento da língua) e que se submete ao discurso acadêmico (o professor precisa, tem que ter).

Entendemos assim, que o discurso da professora contribui para a reiteração de uma identidade de professor de formação deficitária, que entendemos também seja a dela própria, sujeitada pelo discurso da necessidade de inovação ('tem que'; 'não ficar'; 'precisa', 'saber'). Trazemos o excerto novamente, a fim de salientarmos nosso argumento:

[...] o professor também tem que ter uma boa bagagem teórica, não ficar sempre ensinando da mesma forma e as mesmas coisas, precisa se atualizar, saber sobre as novas propostas [...] isto (a metodologia) contribuiu muito para minha formação, já para minha atuação profissional nem tanto, pois a realidade é bem diferente do que é dito na teoria.

Conforme já mencionado, quando se refere ao outro, ela faz pela classe ('o professor'). Distante da classe é como se não pertencesse a ela e expressando seu discurso acentua o posicionamento do professor como objeto de que se fala. Passa então a se referir a um outro, inanimado, que é a metodologia, enquanto componente do curso de graduação. Ao fazê-lo, perpetua um discurso tecnicista, que valoriza a ideia de acúmulo de conhecimento (formação), sendo este distanciado da prática. Esta última ideia projeta uma identidade de professor dependente da aplicação prática, que, subliminarmente, inferioriza a relevância de sua preparação formal.

Assim, as características apresentadas acima, por meio da análise das modalidades, fazem parte do processo de auto identificação dessa professora egressa de língua inglesa. 


\section{Conclusão}

Neste artigo discutimos parcialmente a constituição de identidade de uma professora egressa de um curso de Letras por meio de um questionário piloto por ela respondido. Procuramos responder a duas perguntas gerais: a) No texto produzido pela participante da pesquisa, que componentes da base de conhecimento são imprescindíveis na constituição da identidade docente? e b) Com base em seu texto, que traços identitários inferimos?

Alguns resultados da pesquisa foram os de que, ao produzir o seu texto em relação ao curso de Letras do qual ela era egressa, a participante evidenciou dois componentes da base de saberes imprescindíveis para o profissional docente: a) conhecimento teórico e b) conhecimento linguístico.

Em relação à constituição de sua identidade, por meio de suas representações, ainda ao falar sobre o curso e sobre si mesma nesse contexto, fizemos a inferência de alguns traços, sendo esses traços de um personagem dialógico, um profissional em início de carreira que inferioriza a relevância de sua formação inicial e valoriza o acúmulo de conhecimento para a prática.

\section{Referências}

BAUMAN, Z. Identidade: entrevista a Benedetto Vecchi. Rio de Janeiro: Jorge Zahar, 2005.

CELANI, M. A. A. Ensino de línguas estrangeiras: ocupação ou profissão? In: LEFFA, V. J. O professor de Linguas estrangeiras: construindo a profissão. Pelotas: EDUCAT, 2006. p. 21-40.

CONSELHO DA EUROPA. Quadro europeu comum de referência para línguas: aprendizagem, ensino, avaliação. Porto: ASA, 2001. Disponível em: $\quad<$ http://www.asa.pt/downloads/Quadro Europeu_001_072.pdf $>$. Acesso em: 30 abr. 2011.

CRISTOVÃO, V. L. L. Valorização ou esvaziamento do trabalho do professor. In: ENCONTRO INTERDISCIPLINAR DA EDUCAÇÃO NA
UNIVERSIDADE ESTADUAL DO PARANÁ, 2011, Campo Mourão. Mesa Redonda... Campo Mourão: FECILCAM, 2011.

FAIRCLOUGH, N. A Dialética do Discurso. Revista Teias, v. 11, n. 22, p. 225-234, 2010. Disponível em: $<$ http://pt.scribd.com/doc/55533087/>. Acesso em: 30 abr. 2011.

. Analysing discourse: textual analysis for social research. London: Routledge, 2003.

. Discourse and Social Change. Cambridge: Polity Press, 1992.

FIGUEIREDO, D. C. Linguagem e gênero social: contribuições da análise crítica do discurso e da linguística sistêmico-funcional. DELTA, São Paulo, v. 25, p. 732-754, 2009. Disponível em: $<$ http://www.scielo.br/scielo.php? script $=$ sci arttext\&pid=S0102-44502009000300013\&lng=en $\&$ nrm=iso $>$. Acesso em: 20 set. 2012.

HABERMAS, J.Théoriedel'agircommunicationnel. Paris: Fayard, 1987. t. 1. t. 2.

. Verdade e justificação: ensaios filosóficos. São Paulo: Loyola, 2004.

HALL, S. Quem precisa de identidade? In: SILVA, T. T. (Org.). Identidade e Diferença: a perspectiva dos estudos culturais. Petrópolis: Vozes, 2000. p. 103-133.

HALLIDAY, M. A. K. An introduction to functional grammar. 3. ed. London: Arnold, 2004.

HYPOLITO, A. M. Trabalho docente e profissionalização: sonho prometido ou sonho negado? In: VEIGA, I. P. A.; CUNHA, M. I. (Org.). Desmistificando a profissionalização do magistério. Campinas: Papirus, 1999. p. 81-100.

KINCHELOE, J.; MCLAREN, P. Repensando a teoria crítica e a pesquisa qualitativa. In: DENZIN, N.; LINCOLN, Y. O planejamento da pesquisa qualitativa: teorias e abordagens. Porto Alegre: Artmed, 2006. p. 432.

MATEUS, E. F. Atividade de Aprendizagem Colaborativa e Inovadora de professores: ressignificando as fronteiras dos mundos universidade-escola. 2005. Tese (Doutorado em Linguística e Estudos da Linguagem) - Pontifícia Universidade Católica de São Paulo, São Paulo. 
MEYER, P. The discursive construction of identity and power in the critical classroom: Implications for applied critical theories. Discourse \& Society, Milwaukee, v. 21,n. 2, p. 189-210,2010. Disponível em: <http://das.sagepub.com/content/21/2/189.full. pdf + html $>$. Acesso em: 20 set. 2012.

NÓVOA, A.; HAMELINE, D.; SACRISTÁN, J. G.; ESTEVE, J. M.; WOODS, P.; CAVACO, M. H. Profissão professor. 2. ed. Porto: Porto, 1995. (Coleção ciências da educação)

PAIVA, V. L. M. O. A identidade do professor de inglês. APLIEMGE: ensino e pesquisa, Uberlândia, n. 1, p. 9-17, 1997.

QUEVEDO-CAMARGO, G.; RAMOS, S. M. Reconsiderando pesquisas sobre a identidade profissional do professor de língua inglesa no contexto brasileiro. ActaScientiarium: Language and Culture, Maringá, v. 30, n. 2, p. 189-196, 2008.

QUEVEDO-CAMARGO, G. Avaliar formando e formar avaliando o (futuro) professor de língua inglesa: elementos para um construto. 2011. Tese (Doutorado em Estudos da Linguagem) Universidade Estadual de Londrina, Londrina.

QUEVEDO-CAMARGO, G.; EL KADRI, M. S.; RAMOS, S. M. Identidade do professor de língua inglesa: um levantamento eletrônico das pesquisas no Brasil. In: REIS, S.; VAN VEEN, K.; GIMENEZ, T. (Org.). Identidades de professores de línguas. Londrina: EDUEL, 2011. p. 47-82.

RESENDE, V. M. Análise de discurso crítica: uma perspectiva transdisciplinar entre a linguística sistêmica funcional e a ciência social crítica. In: INTERNATIONAL SYSTEMIC FUNCTIONAL CONGRESS, 33., 2007, São Paulo. Proceedings... São Paulo: LAEL/PUC-SP, 2006. p. 1069-1081.

RESENDE, V. M.; RAMALHO, V. V. S. Análise de discurso crítica. São Paulo: Contexto, 2006.

SHULMAN, L. S. Those who understand: knowledge growth in teaching. Educational Researcher, Standford, v. 15, n. 2, p. 4-14, 1986. 
